\title{
EdWARd SAID E OS PARALELOS ENTRE A OCUPAÇÃo dA PALESTINA E O APARTHEID NA ÁFRICA DO SUL ${ }^{1}$
}

\author{
EdWARd SAid AND the PARALlels betWeen the occupation of Palestine AND APARTHeid in SOUth Africa \\ Fabio Bacila Sahd* \\ fabiobacila@hotmail.com
}

RESUMO: Analisa-se aqui as comparações recorrentes em Edward Said entre a ocupação israelense e o apartheid sul-africano. Buscamos identificar os elementos elencados pelo intelectual para fundamentar esses paralelos, bem como averiguar como essa analogia foi sendo feita ao longo de sua produção. Houve uma mudança de ênfase, ou mesmo de perspectiva? Quais as características de fundo? Para isso recorremos a uma leitura seriada e abrangente das obras saidianas, incluindo seus principais livros, mas também artigos midiáticos e entrevistas. O colonialismo é a principal chave teórica utilizada por Said e pensar esses paralelos nos obriga a revisar sua obra como um todo.

PALAVRAS-CHAVE: Ocupação Israelense; Territórios Palestinos Ocupados; Sionismo.

ABSTRACT: We analyze here Edward Said's recurring comparisons between the Israeli occupation and South African apartheid. We seek to identify the elements listed by the intellectual to support these parallels, as well as to find out how this analogy was made throughout his production. Was there a change in emphasis, or even a change of perspective? What are the background characteristics? For that, we resorted to a serial and comprehensive reading of Saidian works, including their main books, but also media articles and interviews. Colonialism is the main theoretical key used by Said and thinking about these parallels forces us to review his work as a whole.

KEYWORDS: Israeli occupation; Occupied Palestinian Territories; Zionism.

Pensar e escrever sobre Israel/Palestina de forma crítica e contra-hegemônica exige, necessariamente, defrontar-se com processos de invisibilização e silenciamento. Tratando-se do tema, para leigos e leigas o óbvio parece tese demasiado ousada, como as comparações feitas por Edward Said entre ocupação israelense e apartheid sul-africano, respaldadas em um acúmulo suficiente de indícios. Inclusive, desde os anos 1960, ele enfrenta e chama a atenção para os processos de censura em torno da escrita sobre o tema, destacando sua constituição em tabu no universo acadêmico e mesmo nos círculos progressistas, que não hesitam em denunciar violações, desde que não sejam dos direitos do povo palestino. As atrocidades perpetradas pelo antissemitismo na Europa, com a decorrente culpa a ser expiada, ainda pesam sobre os ombros de muitos e muitas, que optam pelo silêncio em se tratando dos palestinos, cujos esforços de descolonização são envidados em diferentes frentes, inclusive na garantia de espaços de fala e produção de saber. Em "A Questão Palestina", Said destaca a

\footnotetext{
${ }^{1}$ Artigo resultante de pesquisa financiada, parcialmente, pelo CNPQ.

* Doutor pelo programa interdisciplinar "Humanidades, direitos e outras legitimidades", da Universidade de São Paulo (USP). Professor na Pontifícia Universidade Católica do Paraná, mais especificamente no curso de Pósgraduação em História Contemporânea e Relações Internacionais.
} 
condição de "vítima das vítimas" e como cerne de sua opressão a condição colonial. Mas observa também um lado positivo, justamente, a colonialidade ser a ponte de seu movimento com o as demais lutas anticoloniais, o que Ihe permitiu auxiliar no empoderamento de algumas delas.

Essas conexões caras à identidade palestina foram reconhecidas por Mandela, em 1991, em conversa com Said, durante a qual lembrou do apoio à luta contra o apartheid, nos piores momentos do Congresso Nacional Africano. Entretanto, a descolonização da Questão Palestina segue na ordem do dia, com sua redução acrítica (quando não cínica) a uma questão de terrorismo reproduzindo as categorias e lógica colonial de silenciamento da alteridade não "ocidental", submetida à opressão, discriminação e desapropriação sistemáticas enquanto sua resistência é esvaziada de densidade história, tentando-se distorcer e silenciar sua narrativa contra-hegemônica. Isso vale para tentativas de equivaler antissionismo e antissemitismo, o que é parte de um regime de silenciamento, como apontam vários autores, a exemplo de Judith Butler. Na contramão, seguem os esforços de escovar essa história a contrapelo, de modo que o anjo de Klee deixe de testemunhar, imobilizado, mais esses episódios de barbárie, como os ataques contra Gaza, em 2014, denunciados pela Rede Internacional de Judeus Antissionistas como um massacre genocida, reivindicando que o slogan clássico "nunca mais" acrescido de "para ninguém".

Há décadas Said ilumina os fragmentos da história palestino-israelense, que ora contextualizaremos sucintamente para, então, apresentar os paralelos feitos com o apartheid. $\mathrm{Na}$ compreensão desse processo, é fundamental evitar as balizas equivocadas, como a consideração dos Territórios Palestinos Ocupados (TPO) descolada do enquadramento espacial, temporal e teórico mais amplo do conflito. Afinal, em muitos sentidos a colonização dos TPO reproduz a lógica e as práticas que acompanham o movimento sionista, desde sua fundação e o estabelecimento das primeiras colônias na Palestina, ainda no final do século XIX. Um exemplo é a transferência populacional que vem, gradativamente, judaizando amplas áreas, limpando-as de sua população palestina e a substituindo por colonos israelenses. É a reprodução, de forma menos abrupta, mas não menos persistente, dos fundamentos colonialistas e nacionalistas exclusivistas que consumaram, em 1948, uma limpeza étnica de grandes proporções, que garantiu a fundação do Estado de Israel como "Estado judeu", expulsando e desapropriando as terras de centenas de milhares de palestinos. 
Repentinamente, a imensa maioria das propriedades fundiárias do país trocaram de mãos, assim como mudou radicalmente sua composição demográfica, consumando a maioria étnica necessária para legitimar um novo Estado etno-nacional (MASALHA, 2000; 2008; PAPPE, 2008).

Fato é que, esse processo de transferência e apartação não se encerrou em 1948, continuando o "apartheid gradativo" ou "furtivo" dentro de Israel e, após 1967, no restante da Palestina histórica, então conquistada, cujas consequências são denunciadas na relatoria de direitos humanos e na bibliografia crítica. As relações dos TPO com Israel não são claras, nem lineares, caracterizando-se por uma ambiguidade, ou "política do caos" (WEIZMAN, 2007), que serve para confundir e dissuadir críticas, ao passo que mantém a lógica irrefreável da judaização do território, que norteia a etnocracia israelense, com as instituições estatais aparelhadas pelo grupo étnico dominante para servir a seus objetivos expansionistas (YIFTACHEL, 2006). Gaza é a consumação do paradigma de "máximo de palestinos no mínimo de terras", ou seja, um espaço reduzido e de confinamento, uma típica reserva nativa colonial ou bantustão, com sua população cercada e controlada em seus movimentos e vida (LI, 2006). Toda a produção intelectual saidiana foi feita acompanhando e considerando esse processo, do qual sua própria biografia dá testemunho e ao qual está entrelaçada, o que, inclusive, é mencionado em vários artigos e livros seus, como "After the Last Sky" e "Fora de Lugar". Said nasceu em Jerusalém, em 1935, e sua família está entre aquelas expulsas, em 1948, passando a viver no exílio (Egito, Líbano e, a partir de 1951, Estados Unidos). Até se graduar, em 1963, voltou, anualmente, ao Oriente Médio para rever sua família. Desde o início de sua profícua trajetória acadêmica, iniciada nos anos 1960 e finalizada com sua morte, em 2003, envolveuse na compreensão e denúncia ativa do colonialismo, orientalismo e sionismo ${ }^{2}$, integrando, inclusive, órgãos diretivos do movimento palestino de libertação, como o Conselho Nacional Palestino (CNP), entre 1977 e 1991.

Contudo, suas reflexões não foram formuladas a partir de um nacionalismo estreito, mas de uma perspectiva inclusiva, humanista e pós-colonial. Esta é teorizada e idealizada como papel social dos intelectuais, ao qual deve ser vinculada toda sua produção crítica, marcada por diferentes influências, como Benjamin, Sartre e Gramsci. Sua definição de

\footnotetext{
${ }^{2}$ Sionismo é o movimento nacional e colonial judaico, surgido na Europa, no final do século XIX, com o intuito de criar o "Estado judeu". Após o descarte de outras opções, a escolha recaiu sobre a Palestina, o que foi consumado com o apoio do imperialismo britânico.
} 
intelectual serviu de fundamentação, enquadramento e teorização de sua própria prática (SAID, 1996a; 2001, p. 283; 2003, p. 248-251; 2007a, p. 163-165; 172). No cerne está a função de "contramemória", criticando posicionamentos legitimadores de opressões, ou falar "a verdade ao e contra o poder", opondo-se aos deliberados silenciamentos para garantir justiça social. O intelectual é outsider, desestabiliza o status quo e questiona estereótipos redutores. Eis o ponto forte da própria trajetória acadêmica e política de Said, percorrida com a produção de obras teóricas e específicas, textos jornalísticos e com participações em programas de rádio e TV, tudo acompanhando seu engajamento direto na Questão Palestina, voltado a incidir na opinião pública. Por suas críticas a Israel, Said esteve exposto a constantes pressões, inclusive, ameaças de morte.

No presente artigo, buscamos iluminar um ponto específico de sua vasta produção: compreender como foi, gradativamente, articulando apartheid sul-africano e Questão Palestina, passando de um entendimento teórico mais abrangente, a partir do colonialismo, até a referência que a luta antiapartheid deveria constituir para o movimento palestino. Eis sua linha principal de atuação e proposta, sobretudo, após ter conhecido mais a fundo a experiência sul-africana, no início dos anos 1990. As relações que faz são multifacetadas e contra-hegemônicas, exemplificando o que entende como papel do intelectual. Apresentaremos os paralelos que traçou, recorrendo a uma exposição que segue os desdobramentos reflexivos do autor ao longo de sua dinâmica trajetória.

\section{Oriente e Palestina, do jovem exilado ao intelectual maduro}

Uma das primeiras reflexões de Said (1970, p. 1-9) sobre as representações mitificadoras dos árabes e os usos ideologizantes da cultura para legitimar Israel e o colonialismo como um todo foi "The Arab Portrayed", publicado logo após a Guerra dos Seis $\operatorname{Dias}^{3}$ e, posteriormente, incorporado em uma coletânea. Nesse breve texto, criticou a representação enviesada dos árabes e, assim, antecipou muitos dos temas aprofundados em obras como A Questão Palestina e Orientalismo, tendo no cerne a questão do colonialismo. Na cinematografia e mídias dos EUA estaria difundida uma "caricatura estúpida e ofensiva", um outro selvagem, massa difusa destituída de personalidade e valores humanos, em

\footnotetext{
${ }^{3}$ A Guerra dos Seis Dias ocorreu em junho de 1967, resultando na expansão israelense sobre o restante dos territórios palestinos (Gaza e Cisjordânia) e na ocupação da Península do Sinai e das Colinas de Golã, aquela negociada e esta formalmente anexada, ao arrepio do direito internacional.
} 
oposição aos "colonizadores brancos". Jargões colonialistas, orientalistas e racistas também estruturariam o discurso sionista, como a representação do "território vazio" e da alteridade bárbara, sem vínculos efetivos com a terra, passível de ser conquistada e fecundada. Dessa visão eurocêntrica derivam várias distorções legitimadoras, como a luta contra a ocupação e colonização israelense ser classificada de terrorista e não "resistência" ou "guerrilha", exigindo-se dos árabes reavaliação de seu passado e presente sem que Israel precise responder por seus atos, como sua existência depender do deslocamento de todo um povo e provocar, continuamente, perda de vidas e propriedades, destruindo vilas inteiras. Sentimentos liberais de justiça, mobilizados para criticar diferentes situações (como Vietnã) não se aplicariam aos palestinos, reduzidos a uma caricatura demonizada, carente de historicidade e de características humanas, embora sejam objeto de admiração no Terceiro Mundo em se tratando de luta anticolonial. Tal situação é explicada pelo bloqueio comunicativo com a opinião pública mundial. Não há referências explícitas à África do Sul, mas ao colonialismo como contexto, até porque, então, o movimento internacional antiapartheid ainda estava em sua fase embrionária.

Entre "The Arab Portrayed" (1967) e a Questão da Palestina (1979), obra esta que sintetiza seu acúmulo sobre o tema até então, Said publicou ao menos três textos curtos específicos, aos quais não tivemos acesso. Seu livro de 1979 pode ser compreendido como um estudo de caso do "Orientalismo", sua obra mais famosa publicada um ano antes, na qual o apresenta como um campo do saber, um imaginário ou forma duradoura de representar a realidade, mais especificamente, a alteridade não europeia, a qual é atribuída uma série de características negativas, infantilizando-a, negando narrativas possíveis, destituindo-a de qualidades humanas reservadas para "nós", "ocidentais". O orientalismo é inseparável do colonialismo, é um produto cultural necessário para justificar o domínio sobre outros povos e a expansão e conquista de suas terras, como já criticado em "The Arab Portrayed". Parte do mundo colonizado, a Palestina não passou incólume, com sua historicidade e luta anticolonial também distorcidas (SAID, 2003, p. 107; 251; 286; 306).

Se o orientalismo fundamenta aproximações entre as experiências na Palestina e na África do Sul tal associação só é feita, explicitamente, a partir de "A Questão da Palestina". Aqui, Said (1992, p. 42; 78-79; 113) enquadra, especificamente, o caso palestino na história mais abrangente do colonialismo, transformador de "territórios desocupados do mundo em 
versões novas da sociedade metropolitana europeia", desconsiderando completamente populações nativas, expulsas ou confinadas em reservas, onde são taxadas e exploradas, enquanto em suas terras originais foram fundadas novas sociedades. São "reconstituições" da Europa em outros espaços, sua multiplicação de forma planejada em locais da Ásia, África e Américas, onde "colonos pioneiros" reproduziram os valores da cultura original. As experiências coloniais têm suas especificidades e generalidades, sobressaindo-se as representações orientalistas e a naturalização das relações coloniais, inclusive das "piores discriminações e exclusões dos nativos” (“'cientificamente' legitimadas”), como ocorrido na África do Sul e Rodésia. Said se dedica à idiossincrasia do caso palestino em meio a esse universo, enfatizando a maior dificuldade de abordar criticamente o sionismo, que sucedeu o colonialismo britânico na região mantendo suas práticas abusivas e representações discriminatórias, pelo tabu do Holocausto e condição palestina de "vítimas das vítimas" de outrora. Assim, predomina o silêncio quanto aos abusos e violações sistemáticas, embora bem documentados, como demolições de casas palestinas, expropriação de terras, exploração de força de trabalho, transferência populacional, deportações, tortura e prisões ilegais.

Ou seja, tanto em "Orientalismo" quanto em "A Questão da Palestina" o sionismo é inserido no contexto mais amplo das barbáries coloniais, mencionando-se na segunda, explicitamente, paralelos com situações análogas, como a África do Sul, com a qual Israel manteve vínculos políticos, diplomáticos e nucleares. Said (1992, p. 204; 234; 119; 214; 184) ilumina convergências e divergências, destacando que se suas vítimas padeceram de males semelhantes, a trajetória dos algozes é distinta. "De modo similar, enquanto em seu tratamento da população árabe nativa é verdade que Israel é um Estado colonizador e se assemelha à África do Sul [...] não há uma similaridade total entre judeus e africâneres". Devido aos "horrores reais do antissemitismo europeu" e ao histórico religioso vinculando judeus à "Terra Santa" a luta anticolonial palestina é mais difícil e complexa, não tendo a linearidade do enfrentamento da maioria negra à discriminação e segregação impostas pela minoria branca em África. O próprio "mundo árabe" ocupa lugar peculiar dentre as demais regiões do Terceiro Mundo e experiências (anti)coloniais. De todo modo, em suas narrativas, visões de mundo e práticas discriminatórias sionismo e nacionalismo africâner convergem, expressando o colonialismo estruturante de ambos, que é o tema central de toda produção saidiana muito influente junto aos teóricos da pós-colonialidade. Se o colonialismo já embasa 
seus primeiros textos, é aprofundado em "Orientalismo" e "A Questão Palestina", livros de maior fôlego que marcam sua maturidade intelectual, nos quais articula saber e poder e as relações entre as potências ocidentais e o mundo "oriental". O tema é retomado em "Cobrindo o Islã", dedicado a manifestações contemporâneas dessa lógica, sobretudo, representações dessa alteridade nos EUA. Pouco depois da publicação dessa obra, em 1981, Said começou a escrever os textos que, na década seguinte, foram compilados, revisados e publicados como "Cultura e imperialismo". Os paralelos entre Palestina e África do Sul se banalizaram em sua produção desde então, sendo o pano de fundo a estrutura colonial comum, refletida na cultura e nas práticas de discriminação, opressão, exploração e resistência.

Said, a Palestina e a África do Sul: dos anos 1980 ao início do processo de paz

"After the Last Sky. Palestinian lives" foi escrito em meados dos anos 1980. Nele, Said (1999) intercala memórias pessoais, testemunhos, descrições históricas, análises e fotografias do cotidiano de pessoas comuns, assim como de figuras renomadas. É, em suas palavras, um registro da "condição palestina" do ponto de vista de um memorialista ou historiador amador, com as contradições e rupturas das trajetórias coletivas e individuais estando refletidas na própria estrutura fragmentária do texto. Said $(1999$, p. $20 ; 133)$ tece, de forma aparentemente aleatória, uma trama da condição palestina, denunciando políticas israelenses, explicitamente, associadas à África do Sul e demais experiências coloniais. A colonização dos TPO visaria a interconexão e continuidade das áreas judaicas enquanto separa, fragmenta e restringe as palestinas. Continuidade para "a população dominante; descontinuidade para nós, os desapropriados e dispersados", a fim de evitar o desenvolvimento econômico e social autônomo, permitindo-se apenas uma melhoria das condições de vida. Manifestações de nacionalismo palestino estão censuradas, pois tal identificação política está proibida e a vida palestina "fragmentada, descontinuada, marcada por arranjos artificiais e impostos de espaços interrompidos ou confinados, pelos deslocamentos e ritmos não sincronizados de um tempo perturbado". A desapropriação, abrupta em 1948, é contínua. Israel nega permissões de construção ou para determinados plantios e controla a água, terra e eletricidade, provocando uma emigração forçada, assim como uma força de trabalho itinerante, explorada dentro do país, onde sequer os palestinos podem dormir, devendo se deslocar diariamente. A definição de judeu e não judeu relega estes à condição de subcidadãos, a um "status de 
terceira classe". Os ocupantes dispõem de meios repressivos como novas expropriações, punições coletivas, abusos, humilhações, demolições, prisões em massa, torturas e assassinatos. Simplificam, sistemática e deliberadamente, a resistência como "terrorista", buscando deslegitima-la. No entanto, falham em criar uma classe de colaboradores e sua truculência alimenta a oposição, revigora a identidade e fortalece a narrativa palestina de autoafirmação e busca da autodeterminação, encabeçada por lideranças como Yasser Arafat e instituições como a OLP, que unificam e garantem coesão, afirmando um nacionalismo não sectário, secular, libertário e igualitário, ou "a política da esperança" (SAID, 1999, p. 104; 112$113 ; 121-122 ; 133 ; 160)$. Paralelos com os bantustões e o apartheid são feitos de forma implícita na maior parte de "After the Last Sky", mas também explicitamente em decorrência da política sistemática de negação, desapropriação e expulsão, criando um mundo colonial à parte e à revelia dos locais, cuja presença, propriedades e vidas são ignoradas. Ao comentar a resistência de estudantes nos TPO (que são sua vanguarda e, por isso, punidos), Said (1999, p. 142) volta a destacar o silêncio generalizado no "Ocidente", com a ausência de petições ou manifestos internacionais de solidariedade. Conformados com o mito da "ocupação israelense 'liberal', ignora-se a colaboração entre Israel, África do Sul "e quase todos os regimes repressivos de direita no Terceiro Mundo" e que vigora "um sistema de praticamente apartheid, no qual os direitos de árabes e judeus são legislativamente desiguais".

Em texto de 1982, Said (1995, p. 60-61) reflete sobre o papel de Israel como mediador das representações orientalistas do Islã nos EUA e no "Ocidente", enquanto aquelas sobre o próprio país são seletivas ou "enviesadas", enaltecendo-o como a "única democracia do Oriente Médio", "bastião da civilização ocidental" em meio às "trevas islâmicas". Assim, ignoram-se elementos destoantes dos valores democráticos, como o caráter religioso e "todas as peculiaridades sociais e ideológicas que, com o passar do tempo, aliaram Israel e África do Sul". Em "Permissão para narrar", de 1984, Said (1995, p. 247-249; 251) volta a abordar as representações coloniais e orientalistas dos palestinos para justificar sua opressão. Enquanto suas instituições e nacionalismo derivariam "da grande onda de sentimento árabe e islâmico anticolonial, pertencendo ao pensamento secular pós-imperialista", o sionismo adviria do nacionalismo europeu, antissemitismo e colonialismo, sendo um "movimento de desapropriação" e negação dos não judeus locais. Suas práticas constituem "brutalidade e opressão, facilmente, comparável aos feitos do regime polonês ou sul-africano", mas tal qual 
na África do Sul a resistência é deslegitimada, negada em sua complexidade, servindo para isso a generalização e uso ambíguo da categoria "terrorista". Mas, enquanto ativistas antiapartheid se mobilizam contra um dos principais aliados de Israel, evitam discutir esse país (SAID, 1995, p. 257-258), cabendo a necessária contranarrativa, desmistificando fatos.

Em artigo de 1985, Said (1995, p. 86-88; 90-93; 105) volta a mencionar o caso sulafricano, dessa vez ao lado do Terceiro Reich, como exemplo de política de diferenciação, fundada na superioridade de um grupo em relação a outro e na tentativa de negar a mestiçagem e homogeneizar a população, valendo-se de representações racistas, perseguição e discriminação organizadas, violando a Declaração de Eliminação de Todas as Formas de Discriminação Racial, aprovada pela ONU, em 1963. De modo análogo, a "diferença" tem sido usada como instrumento por Israel para negar ou relegar a um status inferior os direitos palestinos, expropriando-os e os mantendo na condição de exílio, enquanto estende o "Direito de Retorno" e "nacionalidade" a cidadãos de fé judaica de diferentes países. O Estado judeu foi criado para o "povo judeu". Então a normalidade é definida pela judeidade e a condição normal dos não judeus é a anormalidade, sendo "radicalmente, um outro, fundamentalmente e constitutivamente diferente", seja em Israel seja nos TPO. Essa lógica de inferiorização e construção da ausência abrange a história e a sociedade, estando o exclusivismo e a negação da alteridade já presentes nos fundadores do sionismo, o que se reflete em discursos abertamente discriminatórios, favoráveis a soluções como o "apartheid sul africano", legitimando práticas atrozes. Said $(1995$, p. $84 ; 89 ; 93)$ menciona documentos e autores como Elia Zureik, um dos pioneiros na comparação entre Israel e África do Sul, sobressaindo-se a ideia de "colonialismo interno", mas com pouca circulação no "Ocidente". Estariam evidentes os paralelos entre palestinos e "nativos americanos e sul-africanos negros", com as práticas segregacionistas de Israel ligadas a uma formação ideológica complexa, mas que comunga do repertório colonial. O surgimento do nacionalismo palestino força essa conexão indesejada e denuncia as incoerências entre discurso liberal e práticas racistas, explícitas desde 1967.

Em outros textos dos anos 1980, Said (1995, p. 337-340) seguiu destacando as relações entre sionismo, Israel e práticas similares, como o apartheid, aproximando-as a partir da estrutura econômica e cultural colonial comum. Em texto de 1986 sobre Bernard Lewis, "profícuo e polêmico comentarista neoconservador da Guerra Fria", rebateu sua tentativa de associar antissionismo e antissemitismo. Apontou suas incoerências, dentre elas, várias 
omissões, como a "completa desapropriação dos 'não judeus' [na Palestina]" e o "apartheid na Cisjordânia", assim como "a diferença essencialmente racista entre judeus e não judeus", com o passado de opressão de judeus não podendo servir para ocultar aquela praticada em seu nome por Israel, que marcaria de sua passagem de vítimas a opressores. Em texto de 1988, Said (1995, p. 348) afirma que Israel estaria seguindo o caminho de outros regimes coloniais (como a África do Sul em relação ao Congresso Nacional Africano) ao descrever todos os atos da resistência palestina como "terrorismo". Muitas dessas considerações figuram em entrevista concedida em 1986 e em outras posteriores, na qual denuncia também o tratamento "especializado" do apartheid na África do Sul, "como fenômeno único", e as críticas decorrentes quando é relacionado a situações semelhantes ou conectadas, como Israel (VISWANATHAN, 2002, p. 84-85).

No livro "Acusando as vítimas: bibliografia espúria e a Questão Palestina", publicado em 1988, reúne textos de toda essa década e aborda distintos assuntos. Já na introdução, Said (1988, p. 10; 252) comenta a adesão dos congressistas estadunidenses, ressalvando exceções pontuais, ao lobby e visão sionista, mencionando como ignoram as práticas israelenses nos TPO enquanto as condenam como barbarismo, apartheid ou totalitarismo em lugares como Afeganistão e África do Sul. Em capítulo assinado junto a outros autores palestinos, volta a recorrer ao caso sul-africano, mencionando que, após a ocupação de 1967, que provocou nova expulsão em massa, "políticas semelhantes nas esferas social, cultural e econômica buscam substituir o opressivo sistema de ocupação militar colonial por um sistema de apartheid para a população palestina vivendo sob governo israelense". Israel exila militantes, anexa territórios, confisca terras (cerca de $50 \%$ do total) e constrói colônias, desviando recursos hídricos, o que priva e força palestinos a abandonarem a agricultura, reduzindo-os ao desemprego, à força de trabalho superexplorada e a mercado consumidor de bens produzidos em Israel, comprometendo sua base econômica e social. Mais de um milhão estão sujeitos ao "controle israelense total" e a pressões econômicas e políticas, além de demolições, prisões em massa e censura de instituições culturais. Tais políticas e práticas remontariam aos primórdios do sionismo, expressando um colonialismo duradouro, que expulsa e transforma os remanescentes em "população subordinada", simular à África do Sul.

Paralelos figuram na série de entrevistas concedidas a David Barsamian, entre o final dos anos 1980 e o começo dos anos 1990, reunidas na obra “A caneta e a espada”. Em 1991, 
Said (1994, p. 42; 52-53), inspirado por sua primeira visita ao país africano e desapontado com o que considerou a capitulação das lideranças palestinas, revisitou criticamente muitas questões, como a conexão com as demais lutas anticoloniais, sendo o movimento nacional palestino, até o começo dos anos 1980, o "único no mundo árabe capaz de conectar os palestinos à experiência da colonização". Inclusive, a Intifada seria uma das poucas palavras árabes que entraram na língua inglesa no século XX, sendo uma revolta anticolonial, um dos grandes levantes no Terceiro e Segundo Mundo, aludida em diferentes partes. Mandela Ihe disse que jamais iria abandonar os palestinos por questão de princípios e pela ajuda que deram ao Congresso Nacional Africano (CNA) e a outros movimentos de libertação, com Said destacando "um sentido muito caloroso de associação entre os lutadores palestinos contra a ocupação israelense e a luta contra o apartheid na África do Sul". Tais pontes sugeririam "uma compreensão de nosso próprio lugar na história", como parte desse "grande movimento" anticolonial, o que seria um "feito histórico importante". Mas, o movimento palestino tem suas especificidades no contexto anticolonial. Sobre isso, Said (1994, p. 53-54) avança, traz novas considerações, como ter se tornado o primeiro, "e provavelmente o último", a lutar em um mundo unipolar, sendo a superpotência remanescente "o patrão de nosso inimigo" e não havendo mais um "aliado estratégico", como fora a URSS para outros processos de descolonização. Outra distinção é o entorno palestino, com eles "massacrados" e tendo seu movimento hostilizado nos Estados árabes vizinhos, apesar da retórica de pretenso apoio. 0 objetivo é libertação, mas também soberania nacional em uma parte da Palestina, sendo único também o fato dos palestinos não terem lugar algum no projeto colonial de Israel, sendo desejável que partam ou morram, ao invés de serem explorados como subclasse, a exemplo da África do Sul. Said $(1994$, p. 89; 103; 163) remete ao historiador sul africano Colin Boundy, que afirma ter vigorado em seu país um "colonialismo de tipo especial", havendo uma "classe branca nativa" (e não colonos). Isso se aplicaria, igualmente, aos palestinos, onde há um "colonialismo de um tipo ainda mais especial".

Analogias Palestina/África do Sul figuraram também em outra entrevista a Barsmian, na qual Said (1994, p. 166-167) afirma que estaria fazendo essas comparações com frequência em suas palestras. A linha principal dos políticos israelenses é "basicamente uma noção de apartheid fundamental", com pouquíssimos falando em paz e reconciliação. Já as lideranças palestinas, diferentemente de Mandela e do CNA, foram mudando de posição, abandonando, 
gradativamente, o objetivo inicial de "uma pessoa um voto", como alternativa à ocupação israelense. De um Estado democrático secular, tornou-se um Estado em qualquer parte da Palestina que pudesse ser liberada, depois autonomia, depois autonomia limitada, até a colaboração com os israelenses. Em 1990, Said (1995a, p. 366-371) comparou a linha do CNA e da OLP ao comentar a libertação de Mandela da prisão, colocando sua postura como exemplo para as lideranças palestinas, mais especificamente, a perseverança e abordagem dos fatos como uma questão moral. Acusado de intransigente, Mandela não abriu mão dos princípios do CNA, cujo "conteúdo moral, ao final, triunfou sobre seus adversários", e nunca colaborou com o regime. Se conduta análoga teve o CNP até 1988 (atuando "de uma forma decente, moralmente defensável e politicamente aceitável"), lideranças da OLP estariam, nos bastidores, abrindo mão de princípios universais (libertação e democracia) e suplicando por negociações. Deflagraram assim uma crise ao se afastar da moralidade e perseverança exemplificadas pelo CNA, referência então adotada na oposição de Said ao processo de Paz, que culminou em Oslo e em seu rompimento pessoal com o CNP.

Oslo, o apartheid e depois

A primeira metade da década de 1990 foi um momento fértil da produção intelectual saidiana, dedicada também a revisar os rumos do movimento palestino. Produziu livros como "Cultura e imperialismo" e "Representações dos intelectuais", e também vários artigos, muitos compilados em obras como "The Politics of Dispossession" e "Peace and its descontents". São comuns os paralelos com a África do Sul. Analisando acontecimentos locais e globais que caracterizaram o final da Guerra Fria, amadureceu muitos temas, como as contradições entre nacionalismo e libertação nas lutas anticoloniais e o papel dos intelectuais. Em breve passagem sobre a Guerra do Golfo, escrita em 1991, comparou um passado médiooriental de maior integração, mais multicultural, a um presente de fronteiras fortificadas, em partes devido aos nacionalismos estatais com sua tendência de fragmentar e fraturar. "Líbano e Israel são exemplos perfeitos do que ocorreu. Apartheid, de um modo ou outro, está presente em quase todo lugar, como sentimento grupal, senão como prática, e está subsidiado pelo Estado". Em outro texto sobre a Guerra do Golfo ("outra intervenção imperial", continuidade do colonialismo ocidental) critica Saddam Hussein e demais governos árabes e voltou a comparar a ocupação israelense ao apartheid, denunciando a mediação tendenciosa dos EUA, que veta resoluções condenatórias a Israel no Conselho de Segurança 
da ONU. As partes devem aprender a conviver, reconhecendo-se em sua história e atualidade, superando as representações colonialistas e o presente no qual só israelenses têm soberania e autodeterminação e os palestinos vivem em um "estado de subordinação e opressão". A repressão de sua resistência seria pior do que na África do Sul com, desde o começo da Intifada, centenas de milhares de feridos, muitas mortes, prisões em massa e políticas, desenraizamento de árvores, confisco de terras, demolições, toques de recolher, fechamentos punitivos de áreas e instituições, colonização, censura e deportações, violando dos direitos humanos e humanitários (SAID, 1995, p. 291; 166).

Said contrapõe a queda de muitos governos tirânicos a três localidades onde permanecem hostilidades intercomunitárias: Palestina/Israel, Irlanda e África do Sul. Nesses casos, uma minoria está cercada por uma maioria não reconciliada, mantendo um estado de sítio. Mas, só no território médio-oriental a situação continuaria inalterada e, diferentemente do apartheid, não teria havido sucesso junto à opinião pública mundial em conectar a identidade nacional com a deplorável situação racial. "Hoje, as pessoas podem se opor ao apartheid na África do Sul e não dizer sequer uma palavra sobre as práticas israelenses de apartheid na Cisjordânia e Gaza", com intelectuais boicotando idas ao país africano, mas visitando Israel, sendo que o que foi feito em Gaza é muito pior do que o ocorrido em Soweto, havendo pressão para silenciar críticas contra o "Estado judeu", ofendendo a "consciência intelectual". Enquanto seria cabível os mesmos argumentos e sanções utilizadas contra "governos repressores como o da África do Sul", crimes pretéritos contra judeus são mobilizados para negar ou ofuscar atrocidades praticadas contra os palestinos (SAID, 1995, p. 170-172). Antes mesmo de Oslo, Said já criticou os diálogos de paz recém-iniciados, interpretando-os como viciados.

Em artigo de 1992, Said (1995, p. 194-195) comentou sua viagem à Palestina/Israel, do medo de ter sua entrada barrada até lembranças de infância e a visita a sua antiga casa e aos TPO. Afirma que, quando foi a Gaza vieram à tona também suas lembranças bem mais recentes da viagem à África do Sul. "Nada do que vi na África do Sul pode ser comparado a Gaza em miséria, opressão explícita, confinamento e discriminação racial”. Tal qual um campo de refugiados ao sul de Jerusalém, "Gaza como um todo me impressionou pelo sentido similar de delinquência transportada e depois confinada que você obtém das localidades sul-africanas marginalizadas". Destaca os incontáveis aparatos de segurança e o "grande número de 
soldados 'brancos' patrulhando que você vê na África do Sul". Mas se este sofre condenações e isolamento, Israel é poupado de críticas, "não associado a suas práticas em Gaza".

Talvez, depois de Orientalismo, o livro mais famoso de Said (1995a, p. 11; 400; 320) seja "Cultura e imperialismo", publicado em 1993, mas que começou a ser escrito uma década antes, por volta de 1983, com seu corpo e núcleo de argumentação constituído de materiais reunidos para palestras proferidas em universidades, entre 1985 e 1986 . Nele aprofundou vários temas, especialmente, a relação entre cultura e império ou "entre o Ocidente metropolitano moderno e seus territórios ultramarinos", como os discursos africanistas e indianistas com os estereótipos criados servindo para legitimar a dominação de povos e territórios. Também comparou e criticou lutas anticoloniais, mencionando revoltas populares ao redor do centro do capitalismo internacional, como a contra o apartheid na África do Sul e a ocupação israelense. Mas, se em "Cultura e imperialismo" os paralelos com a África do Sul são circunstanciais, o mesmo não ocorre nos textos reunidos em "Paz e seus descontentes", escritos entre 1993 e 1995. O Processo de Paz, a postura colaboracionista e visão estreita das lideranças palestinas são contrapostas à intransigência de Mandela e do CNA em não abrirem mão de seus princípios igualitários e democráticos e do final inegociável do apartheid, do que Arafat e a OLP estariam cada vez mais distantes, aceitando a submissão e rendição. Ao passo que Said (1996, p. 143-144) não ignora diferenças, questiona essa resignação, contrapondo-a à resiliência de cubanos, vietnamitas e sul-africanos. Reagan e Tatcher apoiaram o apartheid na África, considerando o CNA uma organização terrorista. Suas lideranças foram presas, mas agora são celebradas em todo o mundo. A vitória não veio da bondade repentina de seus oponentes, mas da "visão convincente e inabalável", que derrotou "as atitudes gélidas e imutáveis representadas pelo apartheid", devendo os palestinos seguir esse modelo. Outra lição do CNA seria diferenciar melhor os componentes da sociedade estadunidense, identificando aliados e opositores, sendo necessária organização e acompanhamento dos fatos cotidianos (ouviu essa sugestão de Walter Sisulu, em sua visita à África do Sul).

No processo médio-oriental, as autoridades israelenses estariam sendo arrogantes e intransigentes, não abrindo mão de nada nem negociando os pontos centrais, sequer prevendo o final da ocupação. Já a contraparte palestina, sem ganhar nada, estaria fazendo diferentes concessões enquanto continuam as expropriações, colonização, toques de recolher, assassinatos, prisões. Para piorar, estaria sendo mantida uma lógica de negociação 
secreta, sem consultar as bases, planejar ou sustentar objetivos finais como independência e autodeterminação. Oslo, em si, seria injusto, com os israelenses explorando a fraqueza palestina (potencializada pela corrução de suas lideranças) e mantendo um "regime análogo ao apartheid sul-africano". Apenas realocaram tropas e bases militares (dos centros urbanos da Cisjordânia para suas margens), mantendo sua liberdade de ação e impunidade, assim como dos colonos, ao passo que controlam todas as estradas e entradas e saída dos territórios palestinos, limitando sua autonomia, privando-os de domínio efetivo sobre a segurança, recursos e as terras fora das "áreas A". Um sistema de estradas conectará as colônias entre si, possibilitando a seus moradores "evitar ou mesmo nunca ver as pessoas dos bantustões [...] impossibilitando aos palestinos governar em qualquer território contíguo", como foi no apartheid. O horizonte não é criar o Estado palestino, mas um protetorado ou "versão médiooriental dos bantustões sul-africanos". De líder do povo Arafat se tornou um "Buthelezi israelense, ou o administrador de um bantustão", sendo sua grande conquista autonomia "em meia dúzia de cantões ou guetos separados", "uma série de responsabilidades municipais em bantustões dominados do exterior por Israel", que conseguiu "consentimento oficial palestino para continuar a ocupação", terceirizando a aplicação das leis (SAID, 1966, p. 147-148; 70-75; 121). Em outro texto, Said (1996, p. 63-67; 95; 139) menciona e se alinha a um pronunciamento feito por lideranças independentes dos TPO, descontentes com Oslo e que fazem críticas semelhantes a como Israel segue explorando a terra e seus recursos, encoberto agora pelo manto das negociações para violar as resoluções da ONU e tentar legitimar ações ilegais pretéritas. Mas destaca ser tarde para lamentar a "a falácia de Oslo" e a postura de seus atores. Seria inviável administrar a "jurisdição mista" ("uma lei para os colonos israelenses outra para os palestinos") e esperar algo além da ocupação militar, de mais demonstrações de poder e que "esse estado de apartheid continuará, por óbvio". A questão seria o que fazer. Mais uma vez, o exemplo é o movimento antiapartheid, mas também a própria Intifada, cuja energia ainda estaria circulando, constituindo-se em esperança. Deve-se recusar a colaboração e avançar na luta de massas, de desobediência civil e contrahegemônica, mobilizada de baixo para cima, e em um programa paralelo, envolvendo todo o povo palestino e os setores críticos da sociedade israelense, desconstruindo mitos e divulgando a justeza moral da Questão Palestina a fim de fortalecer a campanha internacional por seus direitos. A luta está longe de terminar, cabendo inserir nas reivindicações reparações por todas as perdas, desde 1948, e o fim imediato da colonização e ocupação. Isso passa por: 
disputar internamente a condução do movimento palestino, aumentando sua organicidade e capilaridade; fortalecer a demanda por liberdades democráticas; informar/mobilizar o povo; fazer o contraponto junto à opinião pública internacional; e romper o monopólio da OLP sobre as finanças e produção e circulação de informações. Arafat, antes de renunciar, deveria olhar para os verdadeiros recursos de seu próprio povo (sua crença na justiça e liberdade), confiando nele.

Em "The End of the Peace Process" encontramos produções saidiana reiterando muitos pontos e dando retoques finais em sua oposição a Arafat e a Oslo. Na introdução, Said (2001, p. XIV-XVI; XXII) ataca o próprio fundamento do processo de paz: a errônea concepção de "exclusivismo sectário", separando as pessoas em Estados homogêneos. A era das partições e separações, iniciada em 1948 e cujos princípios fundamentaram Oslo, só teria trazido catástrofe, e assim prosseguiria. Basta de "falatórios", "regimes de separação" e desse "novo nome dado ao apartheid", expediente para manter o status quo, apenas reconfigurando a ocupação israelense ou as "muitas políticas de apartheid ainda em vigor que discriminam explicitamente os palestinos em bases étnicas e religiosas". Para uma paz verdadeira cabe rever suas premissas e as adequar a uma concepção alternativa de passado, presente e futuro, baseada em consciência histórica, no reconhecimento do outro e das reivindicações não atendidas e na coexistência justa e decente, igualdade e autodeterminação, que fundamente um "novo sentido de modernidade", fazendo com que palestinos adentrem na vanguarda humana, ao lado dos sul-africanos, conectando sua luta por justiça com todo o mundo (SAID, 2001, p. 334). Em "Mandela, Netanyahu e Arafat" (de 1996) Said sobe o tom das críticas ao último, que teria "aceitado o inaceitável" em nome de um falso "realismo", tornando-se "colaboracionista" para governar em pequenos bantustões, ignorando direitos básicos dos palestinos, seu anseio de plena autodeterminação e alienando a força moral de sua causa. A alternativa é a mesma mencionada há pouco, que deve atrair e envolver também israelenses opositores do racismo, reforçando que é para ficarem e partilharem da mesma terra com base em direitos iguais. "Apenas a visão de uma Palestina multicultural e democrática pode inspirar tal movimento", sendo a luta uma por "democracia ou direitos iguais, por uma comunidade de nações secular ou Estado no qual todos seus membros sejam cidadãos iguais". O CNA é exemplar, assim como as comissões de verdade e reconciliação criadas na transição do apartheid. Trata-se de um retorno ao programa original 
da OLP, o que ficou explícito em "Como se soletra Apartheid? O-S-L-O" (de 1998), no qual defendeu um "Estado secular binacional" ao invés dos dois Estados étnicos como "autogoverno" tutelado e não "autodeterminação", uma "separação" como "sinônimo de apartheid, não de libertação". Primeiro, deve-se vencer o colonizador no plano moral, deslegitimando-o na arena internacional. Então negociar e acabar com seu isolamento. Said admite que tal visão decorreu de sua primeira visita à África do Sul, mencionando que organizou em Londres um seminário junto com o embaixador do CNA para versar sobre essa experiência e o proveito de reproduzi-la na Palestina, constituindo uma campanha massiva de boicote e informação, organizando comitês e intervenções em diferentes espaços (SAID, 2001, p. $64-68 ; 195 ; 247 ; 258 ; 279-286 ; 359-363)$.

Em escrito posterior, Said (2001, p. 110) avalia os acordos de Oslo e a autonomia garantida aos palestinos como uma "amalgama bizarra de três 'soluções' históricas descartadas, vislumbradas por colonizadores brancos para o problema nos nativos no século XIX na África e Américas". Primeiro, torna-los "exóticos irrelevantes", privados de suas terras e reduzidos a trabalhadores ou "agricultores pré-modernos" ("modelo indo-americano"). Segundo, divisão das terras em reservas, "bantustões não contínuos, com uma política de apartheid dando privilégios especiais aos brancos (hoje, israelenses) enquanto os nativos são deixados a viver em seus guetos" com autonomia relativa ("modelo sul-africano"). Terceiro, para dar algum grau de legitimidade local a esses arranjos, obter a colaboração de um líder local, elevando seu status e dando poderes, como uma força policial nativa (modelo francobritânico para a África do século XIX), sendo Arafat um equivalente. Em outro texto, compara práticas israelenses e sul-africanas, destacando a discriminação e segregação em Israel e nos TPO com respaldo do judiciário (eles "têm' seu próprio sistema", sendo este eufemismo similar ao utilizado pelo apartheid sul-africano). Conclui que vigora um "sistema de apartheid", não havendo mais continuidade entre as áreas palestinas, e estes estão reduzidos "a uma condição similar aos negros sob o apartheid e dos indígenas americanos nas reservas [...] Isto é apartheid racista" (SAID, 2001, p 269-270; 103; 165; 171; 251-253).

Entre 1999 e 2003, Said concedeu outras entrevistas a Barsamian, reunidas no livro "Cultura e resistência", reforçando esses temas, assim como "a solução de um Estado binacional" contraposta à inviabilidade da partilha e do "sistema de apartheid para os palestinos". Nas reservas nativas da África do Sul, tal qual nos TPO, haveria "alguns atributos 
da soberania, mas nenhuma real", tampouco controle sobre a terra, a água ou a entrada e saída dos territórios, prevalecendo um estado de sítio, uma "sufocação econômica" constante. "Sentimentos racistas" se banalizam enquanto a política israelense é "incessantemente ativa em oprimir e dominar os palestinos com métodos que superam de longe qualquer coisa que já tenha sido feita na África do Sul durante o apartheid". Por outro lado, estaria ascendendo um "movimento de desinvestimento nos campus das universidades americanas que exigem que estas desinvistam nas companhias que fazem negócios com Israel", seguindo "o padrão do movimento antiaparhteid na África do Sul nos anos 1970 e 1980", malgrado as tentativas de deslegitimar esses esforços como expressão de antissemitismo assim como as comparações com o apartheid sul-africano, apesar dos "milhões de relatórios" de ONGs e da ONU. A retórica ainda é colonial: os palestinos "exageram", "não sentem o mesmo que a gente", não partilham dos mesmos valores (SAID, 2006, p. 19-20; 50; 79-82; 62-63; 70; 151; 176).

Seus últimos artigos midiáticos, escritos entre 2000 e 2003, foram compilados na obra "From Oslo to Iraq and the Roadmap". Abundam os paralelos com a África do Sul e demais realidades coloniais, entendidos como necessários por garantirem lições úteis ao movimento de libertação palestino, desde que não se negue as especificidades. Inclusive, em dois textos, Said volta a comentar suas duas idas ao país africano e o aprendizado que teve com Mandela. Ao final do livro, há um posfácio feito por sua filha, que destaca o "profundo efeito" dessas visitas na visão de seu pai sobre a luta palestina, que deveria seguir o "modelo sul-africano" (SAID, 2005, p. 29-30; 241). A crítica, agora, também recai sobre a via armada, as táticas terroristas e a resistência islâmica, por debilitarem a "batalha cultural" e moral, o movimento de massas e uma alternativa não exclusivista nem beligerante. A alternativa segue a mesma: includente e secular, fundada na coexistência, na "humanidade comum". "O apartheid sul-africano só foi derrotado porque negros, assim como brancos, combateram-no [...] gostemos ou não, a Palestina histórica é agora uma realidade binacional sofrendo a devastação do apartheid.". Cabe ao movimento palestino sinalizar o caminho, defendendo "dois povos em uma terra" e "igualdade para todos" em um Estado binacional (ou em dois Estados, desde que garantam coexistência e relações baseadas na igualdade e soberania). A ocupação é um "apartheid na prática", mantido por um "sistema legal oculto" que discrimina palestinos dentro de Israel e nos TPO. Said menciona um jornalista sul-africano que assim 
relatou sua ida à Gaza em um jornal local: "o apartheid nunca foi tão perverso e desumano como o sionismo: limpeza étnica, humilhações diárias, punições coletivas em grande escala, desapropriação de terras, etc", além da redução deliberada à miséria e ao desemprego. Analogias feitas em termos semelhantes igualmente figuram em falas de Desmond Tutu e Nelson Mandela (SAID, 2005, p. 41; 49-50; 61; 93; 102; 118; 169-171; 186-187; 281).

\section{Conclusão}

No terceiro milênio, já há acúmulo suficiente de indícios para sustentar que está em curso na Palestina/Israel um processo de discriminação e segregação semelhante ao sulafricano. Além de Said e da bibliografia crítica, centenas de relatórios da ONU e de ONGs fundamentam essa constatação, inusitada somente para leigos e leigas. Exemplificando essa documentação, há quase cinquenta anos, em dezembro de 1971, a resolução 2851 (XXVI) da Assembleia Geral da ONU instou Israel a desistir da "[...] evacuação, transferência, deportação e expulsão dos habitantes dos territórios árabes ocupados" e da "[...] destruição e demolição de aldeias, quarteirões e casas, e do confisco e expropriação de propriedades" (UNITED NATIONS, 1971). Quatro décadas depois, em 2014, o relator especial apontado pelo Conselho de Direitos Humanos da ONU (CDH-ONU) para apurar as violações praticadas por Israel nos TPO denunciou a opressão, exploração, discriminação e apartação como um todo, em consonância com o que chamou de "evidentes objetivos anexionistas, colonialistas e de limpeza étnica de Israel", recorrendo à palavra hebraica hafrada para definir a situação e a utilizando como sinônimo do termo apartheid (UNITED NATIONS, 2014). Em relatório publicado pouco antes, a ONG internacional Human Rights Watch (2010, p. 1-3) também constatou que vigora nos TPO uma separação e desapropriação gradativa, sob um "sistema dualista de leis, regras e serviços de Israel para as duas populações de áreas da Cisjordânia sob seu controle exclusivo", com base em critérios raciais, étnicos e de origem nacional. Para os palestinos, deslocamento forçado e práticas administrativas que restringem seu território e impõe duras condições. Para os israelenses, crescimento das colônias, privilégios, desenvolvimento e benefícios. Poderíamos nos estender muito mais pela documentação e bibliografia que comparam TPO e África do Sul do apartheid (ABUNIMAH, 2006; BISHARA, 2003; COCONI, 2010; OSMAN; DADDO, 2013; UNITED NATIONS, 2007; 2017; YIFTACHEL, 2006; WHITE, 2014). 
As reflexões de Said têm lastro nessa documentação e nelas o apartheid serve tanto de analogia como de tipologia para enquadrar e condenar a ocupação israelense, além da luta contra ele ter o papel de contraponto crítico e modelo a ser seguido, engajando também israelenses progressistas. Desde "o jovem Said", o colonialismo é a categoria central e o eixo comum conectando essas situações análogas de discriminação, exploração, opressão e segregação. Isso está explícito e foi reafirmado, constantemente, em toda sua trajetória intelectual. A Palestina é enquadrada como uma questão estritamente colonial, portanto, de opressão, que como tal deve ser criticada pelos intelectuais, muito além de mero engajamento étnico, e daí os paralelos com o apartheid. A identificação da colonialidade comum tem sentido crítico, mas também carrega um sentido de esperança, reconhecimento e inclusão do outro na luta de libertação anticolonial, teorizada em "Cultura e imperialismo". Trata-se de redimir o passado no presente e garantir um futuro de "reconciliação histórica" e coexistência (SAID, 1994, p. 18-19; VISWANATHAN, 2002, 426; 446). Apesar de sua aguçada capacidade analítica, talvez Said tenha sido simplista em suas críticas a Arafat. É evidente a divergência tática e estratégica, mas entre isso e a acusação de "colaboracionismo" há um fosso. Acaso estivesse vivo, Said talvez reconsiderasse o papel da AP a partir da assinatura, na década de 2010, de diferentes tratados internacionais, sobretudo o Estatuto de Roma, acionando o Tribunal Penal Internacional para avaliar os crimes cometidos por Israel, o que pode o deslegitimar e isolar, assegurando a vitória no plano moral.

\section{REFERÊNCIAS BIBLIOGRÁFICAS}

ABUNIMAH, Ali. One country: A bold proposal to end the Israeli-Palestinian impasse. New York: Metropolitan books/Henry Holt and Company, 2006.

BISHARA, Marwan. Palestina/Israel: a paz ou o apartheid. São Paulo: Paz e Terra, 2003.

COCONI, Luciana. Apartheid contra el pueblo palestino. Madrid: Ediciones del Oriente y del Mediterráneo, 2010.

HUMAN RIGHTS WATCH. Separate and Unequal: Israel's Discriminatory Treatment of Palestinians in the Occupied Palestinian Territories. New York: Human Rights Watch, 2010.

LI, Darryl. The Gaza Strips as Laboratory: Notes in the Wake of Disengagement. Journal of Palestine Studies, vol. XXXV, no. 2, 2006.

MASALHA, Nur. Imperial Israel and the Palestinians: the politics of expansion. London: Pluto Press, 2000.

MASALHA, Nur. Expulsión de los palestinos. El concepto de "transferencia" en el pensamiento político sionista, 1882-1948. Buenos Aires: Editorial Canaán, 2008. 
OSMAN, Firoz; DADOO, Suraya. Why Israel? The anatomy of Zionist apartheid - a South Africa perspective. Johannesburg: Media Review Network; Porcupine Press, 2013.

PAPPE, Ilan. The ethnic cleansing of Palestine. Oxford: Oneworld Publications, 2008.

SAID, Edward W. (et al). A profile of the Palestinian people. In: SAID, Edward W.; HITCHENS, Christopher (ed.). Blaming the victims: spurious scholarship and the Palestine Question. London: Verso, 1988.

SAID, Edward W. The Arab Portrayed. ABU-LUGHOD, Ibrahim (ed.). The Arab-Israeli confrontation of June 1967. An Arab Perspective. Evanston: Northwestern University Press, 1970.

SAID, Edward W. The Question of Palestine. New York: Vintage Books, 1992.

SAID, Edward W. The Pen and the Sword. Conversations with David Barsamian. Monroe: Common Courage Press, 1994.

SAID, Edward W. The Politics of Dispossession. The Struggle for Palestinian Self-Determination, 19691994. New York: Vintage Books, 1995.

SAID, Edward W. Cultura e imperialismo. São Paulo: Companhia das Letras, 1995a.

SAID, Edward W. Peace and its discontents. Essays on Palestine in the Middle East Peace Process. New York: Vintage Books, 1996.

SAID, Edward W. Representations of the intellectual. New York: Vintage Books, 1996a.

SAID, Edward W. Covering Islam. How the Media and the Experts Determine How We See the Rest of the World. London: Vintage Books, 1997.

SAID, Edward W. How do You spell Apartheid? O-S-L-O. Ha'aretz, October 11, 1998. Disponível em:<http://www.edwardsaid.org/articles/how-do-you-spell-apartheid-o-s-l-o/>. Acesso em: 5 mai. 2020.

SAID, Edward W. After the Last Sky. New York: Columbia University Press, 1999.

SAID, Edward W. Fora do lugar. Memórias. São Paulo: Companhia das Letras, 1999a.

SAID, Edward W. The End of the Peace Process. Oslo and After. New York: Vintage Books, 2001.

SAID, Edward W. Reflexões sobre o exílio e outros ensaios. São Paulo: Companhia das Letras, 2003.

SAID, Edward W. Cultura e resistência: entrevistas do intelectual palestino a David Barsamian. Rio de Janeiro: Ediouro, 2006.

SAID, Edward W. Orientalismo: o Oriente como invenção do Ocidente. São Paulo: Companhia das Letras, 2007.

SAID, Edward W. Humanismo e crítica democrática. São Paulo: Companhia das Letras, 2007a.

UNITED NATIONS. General Assembly. Resolution 2851 (XXVI). Report of The Special Committee to Investigate Israeli Practices Affecting the Human Rights of the Population of the Occupied Territories. UN, December 20, 1971.2 Disponível 
<https://unispal.un.org/DPA/DPR/unispal.nsf/0/DC39D8D9B0DADCF6852560DE006B70B5>. Acesso em: 22 abr. 2020.

UNITED NATIONS. Human Rights Council. Implementation of General Assembly Resolution 60/251 of 15 March 2006 Entitled "Human Rights Council". Report of the Special Rapporteur on the situation of human rights in the Palestinian territories occupied since 1967, John Dugard. UN, January 29, 2007. Disponivel em: <https://documents-ddsny.un.org/doc/UNDOC/GEN/G07/105/44/PDF/G0710544.pdf?OpenElement>. Acesso em: 22 abr. 2020.

UNITED NATIONS. Human Rights Council. Human Rights Situation in Palestine and other Occupied Arab Territories. Report of the Special Rapporteur on the situation of human rights in the Palestinian territories occupied since 1967, Richard Falk. UN, January 13, 2014. Disponível em: <http://blog.unwatch.org/wp-content/uploads/A-HRC-25-67_en-Falkfinalreport_Feb2014.pdf>. Acesso em: 19 jan. 2014.

UNITED NATIONS. Economic and Social Commission for Western Asia. Israeli Practices towards the Palestinian People and the Question of Apartheid. United Nations: Beirute, 2017. Disponível em:<https://www.middleeastmonitor.com/wp-content/uploads/downloads/201703_UN_ESCWAisraeli-practices-palestinian-people-apartheid-occupation-english.pdf>. Acesso em: 27 mar. 2017.

VISWANATHAN, Gauri (ed.). Power, politics and culture. Interviews with Edward W. Said. New York: Vintage Books, 2002.

YIFTACHEL, Oren. Ethnocracy. Land and identity politics in Israel/Palestine. Philadelphia: University of Pennsylvania Press, 2006.

WEIZMAN, Eyal. Hollow Land: Israel's architecture of occupation. London: Verso, 2007.

WHITE, Ben. Israeli apartheid: A beginner's guide. 2. ed. London: Pluto Press, 2014. 